\title{
Study to evaluate the effectiveness of Planned Teaching Programme regarding prevention of post operative pulmonary complications among patients undergoing laprotomy in PGIMS, Rohtak, Haryana
}

\author{
Mrs. Baby Bansal ${ }^{1,}$ Mrs. Poulomi Roy ${ }^{2}$ \\ ${ }^{1}$ Masters in Medical Surgical Nursing, College of Nursing, PGIMS, Rohtak, Haryana \\ ${ }^{2}$ Bachelors of Science in Nursing Sister Florence College of Nursing, Kolkata
}

\begin{abstract}
A Quasi Experimental study was conducted to evaluate the effectiveness of Planned Teaching Programme regarding prevention of post operative pulmonary complications among 60 patients undergoing laprotomy in PGIMS, Rohtak, Haryana by using purposive sampling technique. Structured interview knowledge questionnaire was used to assess the knowledge of patients undergoing laprotomy. The findings of the study revealed that the mean post test scores were significantly higher than mean pre scores.
\end{abstract}

Keywords: Planned Teaching Programme, Post operative pulmonary complications, Patients, Laprotomy, PGIMS

\section{Introduction}

"Intelligent, consciousness, pre operative nursing contributes much to having the patient achieve an optimum condition that favors a satisfactory postoperative progress and minimizes the possibility of complication"

Surgery is one of the most ancient arts in the world. Its oldest branch, obstetrics surgery, is almost as old as the world itself. Any type of surgery is stress to the patient. It becomes even more stressful when the vital organs are involved. Having surgery is a major event in any person's life. Some of the patient may respond with expression of helplessness, security and isolation due to discomfort, pain and fear of breaking stitches. These feeling can be minimized with pre operative teaching about postoperative practice related to activities, nutrition, medication and ambulation ${ }^{1}$. Laprotomy is a major surgery which may lead to post pulmonary complications like pneumonia, atelectasis, pneumothorax, respiratory failure, pleural effusion, pulmonary embolism, bronchitis, and bronchospasm ${ }^{2}$. Post operative pulmonary complications increase the length of hospital stay. So, it is necessary to prevent these by improving knowledge regarding its preventing measures.

"Prevention is better than cure"

A study was conducted regarding chest physiotherapy during immediate post operative period among patients undergoing abdominal surgery. Chest physiotherapy during immediate post operative period following laprotomy was effective for improving oxygen hemoglobin saturation without increased abdominal pain. Breathing exercises could be adopted post anesthesia care units with benefits for patients (Paulo et al. (2009) ${ }^{3}$.

A study was conducted in New Delhi to evaluate the efficacy of breathing exercise over chest physiotherapy in preventing respiratory complications among laprotomy patients. One hundred and fifty patients were selected and total group divided into three groups, one group were given deep breathing exercise manually, group two with chest physiotherapy and group three as a control group. Development of complication rate for group one and group two was less than ten percent, and for group three was 48 percent. Researcher concluded the study as both deep breathing exercise and incentive spirometry were effective for prevention of POPC (Neeraj V, 2009).

A study was conducted on effective of preoperative instructions on postoperative out come. A study comprised of 4018 subjects divided in to 2 groups the experimental groups comprised of 2413 patients and in the control groups 1605 subjects. The experimental groups were given preoperative teaching on respiratory exercises, leg exercises and getting out of the bed in order to prevent postoperative pulmonary complications whereas the pre-operative teaching was without to the control group. The results showed that the patient received any form of preoperative instruction had more favorable outcomes than $67 \%$ of a similar group who did not receive preoperative instruction. There was a $20 \%$ improvement in postoperative outcome in the experimental group (Jawaid M, Masood Z, 2006) $)^{5}$.

Aim and Objective of the Study

$>$ To evaluate the effectiveness of Planned Health Teaching Programme regarding prevention of post operative pulmonary complications among patients undergoing laprotomy. 


\section{Materials and Methods}

The present study was conducted to evaluate the effectiveness of Planned Health Teaching Programme regarding prevention of post operative pulmonary complications among 60 patients undergoing laprotomy in PGIMS, Rohtak, Haryana. Quasi Experimental research design was used in the study using purposive sampling technique and sample size was 60. Data was collected by structured interview knowledge questionnaire regarding prevention of post operative pulmonary complications of patients undergoing laprotomy in PGIMS, Rohtak, Haryana in the month of January and February 2014. Descriptive and inferential statistics were employed to analyze the data.

Observations

\begin{tabular}{|c|c|c|c|c|c|c|c|}
\hline \multirow[t]{2}{*}{ Sr. No } & \multirow[t]{2}{*}{ Variables } & & \multirow[t]{2}{*}{ Demographic variables } & \multicolumn{2}{|c|}{ Frequency } & \multicolumn{2}{|c|}{ Percentage } \\
\hline & & & & Expt. & Control & Expt. & Control \\
\hline \multirow[t]{4}{*}{1.} & Age (in years) & a) & $<25$ years & 4 & 3 & $13 \%$ & $10 \%$ \\
\hline & & b) & $26-40$ years & 9 & 10 & $30 \%$ & $33 \%$ \\
\hline & & c) & $41-55$ year & 12 & 8 & $40 \%$ & $27 \%$ \\
\hline & & d) & $>55$ years & 5 & 9 & $17 \%$ & $30 \%$ \\
\hline \multirow[t]{2}{*}{2.} & Sex & a) & Male & 27 & 23 & $90 \%$ & $77 \%$ \\
\hline & & b) & Female & 3 & 7 & $10 \%$ & $23 \%$ \\
\hline \multirow[t]{5}{*}{3.} & Education & a) & Illiterate & 9 & 12 & $30 \%$ & $40 \%$ \\
\hline & & b) & $1-5^{\text {th }}$ & 4 & 6 & $13 \%$ & $20 \%$ \\
\hline & & c) & $6-12^{\text {th }}$ & 13 & 10 & $44 \%$ & $33 \%$ \\
\hline & & d) & Graduation & 3 & 2 & $10 \%$ & $07 \%$ \\
\hline & & e) & Post-graduation & 1 & 0 & $03 \%$ & 0 \\
\hline \multirow[t]{5}{*}{4.} & Occupation & a) & Unemployed & 8 & 8 & $27 \%$ & $27 \%$ \\
\hline & & b) & Self business & 4 & 6 & $13 \%$ & $20 \%$ \\
\hline & & c) & Farmer & 8 & 6 & $27 \%$ & $20 \%$ \\
\hline & & d) & Govt. service & 3 & 2 & $10 \%$ & $07 \%$ \\
\hline & & e) & Labourer & 7 & 8 & $23 \%$ & $26 \%$ \\
\hline \multirow[t]{4}{*}{5.} & Religions & a) & Hindu & 30 & 30 & $100 \%$ & $100 \%$ \\
\hline & & b) & Muslim & 0 & 0 & 0 & 0 \\
\hline & & c) & Sikh & 0 & 0 & 0 & 0 \\
\hline & & d) & Others & 0 & 0 & 0 & 0 \\
\hline \multirow[t]{4}{*}{6.} & Marital status & a) & Married & 28 & 27 & $93 \%$ & $90 \%$ \\
\hline & & b) & Unmarried & 2 & 3 & $07 \%$ & $10 \%$ \\
\hline & & c) & Widow & 0 & 0 & 0 & 0 \\
\hline & & d) & Divorce & 0 & 0 & 0 & 0 \\
\hline \multirow[t]{2}{*}{7.} & Type of family & a) & Nuclear & 20 & 22 & $67 \%$ & $73 \%$ \\
\hline & & b) & Joint & 10 & 8 & $33 \%$ & $27 \%$ \\
\hline \multirow[t]{4}{*}{8.} & Monthly income & a) & $5000-10,000$ & 15 & 14 & $50 \%$ & $47 \%$ \\
\hline & & b) & $11,000-20,000$ & 12 & 11 & $40 \%$ & $37 \%$ \\
\hline & & c) & $21,000-40,000$ & 3 & 5 & $10 \%$ & $16 \%$ \\
\hline & & d) & $>40,000$ & 0 & 0 & 0 & 0 \\
\hline \multirow[t]{2}{*}{9.} & Living area & a) & Rural & 24 & 25 & $80 \%$ & $83 \%$ \\
\hline & & b) & Urban & 6 & 5 & $20 \%$ & $17 \%$ \\
\hline \multirow[t]{4}{*}{10.} & Habits & a) & Smoking & 12 & 10 & $40 \%$ & $34 \%$ \\
\hline & & b) & Smoking+ Alcohol & 9 & 4 & $30 \%$ & $13 \%$ \\
\hline & & c) & Tobacco chewing & 3 & 6 & $10 \%$ & $20 \%$ \\
\hline & & d) & No any above habit & 6 & 10 & $20 \%$ & $33 \%$ \\
\hline
\end{tabular}

\section{Results}

The study articulated that the mean post test knowledge score of experimental group 20.86 was significantly higher than mean post test knowledge score of control group 12.3. The ' $\mathrm{T}$ ' Value calculated was found to be greater than ' $T$ ' Value tabulated at 0.05 level of significance (P Value). Hence, null hypothesis was rejected and Planned Health Teaching Programme was found to be effective.

Figure 1- Post Test Knowledge Mean Scores of Study Subjects

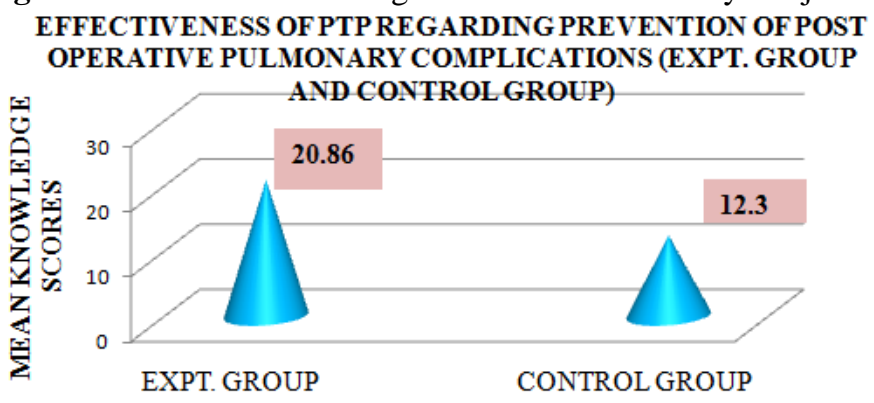


Figure 1 represents the mean of knowledge scores of Experimental and Control Group i.e. Post Test Knowledge Mean Scores.

Mean, Range and SD of knowledge and attitude scores regarding Road Safety Measures

\begin{tabular}{|l|l|l|l|l|l|l|l|}
\hline COMPONENTS & MAX. SCORE & RANGE & MEAN & SD & $\mathbf{T}_{\text {Cal }}$ & P Value & T $_{\text {Tab }}$ \\
\hline $\begin{array}{l}\text { Post test scores } \\
\text { (Experimental Group) }\end{array}$ & 30 & $27-14=13$ & 20.86 & 3.05 & 11.8 & 0.05 & 2.01 \\
\cline { 1 - 1 } & $\begin{array}{l}\text { Post test scores (Control } \\
\text { Group) }\end{array}$ & 30 & $18-8=10$ & 12.3 & 2.54 & & \\
\hline
\end{tabular}

\section{Discussion}

The present study was conducted to evaluate the effectiveness of Planned Health Teaching Programme regarding prevention of post operative pulmonary complications among 60 patients undergoing laprotomy in PGIMS, Rohtak, Haryana. The findings in the present study were supported by Lee DS, Chein WT (2002) conducted a study to evaluate the effect of a nine weeks exercise programme that emphasized aerobic and upper body strength on the maximal voluntary ventilation of patients with chronic obstructive pulmonary disease. Study comprised of 50 patients divided in to 2 groups. The experimental groups were given a teaching health promotion through respiratory exercises and demonstration of exercises but it was withhold to the control group. The result showed a significant difference between the pretest and posttest scores within the experimental groups on knowledge level about their disease and its control. There was no significant difference when compared the knowledge and practice results between pre test and post scores within the control group. There was significant difference when compared the control group, practice scores with the experimental group scores ${ }^{6}$.

\section{References}

[1]. Malcolm R. Calmer Moroney's Surgery for Nurses. $16^{\text {th }}$ Edition. 2002; Pp 1-25.

[2]. Priseilla. K Gazarian. Identifying risk factors for postoperative. AORN Journal. 2006.

[3]. Paulo.et al. Chest Physiotherapy during immediate post operative period among patients undergoing abdominal surgery. Sao Paulo Medical Journal. 2009.

[4]. Andre Veldman. Prevention of Pulmonary Complications after upper abdominal surgery. Journal of Clinical Rehabilitation. 2008; Pp 134-142.

[5]. Jawaid M, Masood Z, Iqbal SA. Post operative complications in general surgical ward of a teaching hospital. Pak J Med Sci. 2006; 22(2).

[6]. Lee DS, Chein WT. Pre-operative patient teaching in an acute care ward in Hong Kong: Contemporary Nurse. 2002. 